\title{
O processo mais breve diante do Bispo ${ }^{1}$
}

\author{
The briefest process before the Bishop
}

Resumo: A denominação do processo em relação à sua natureza; os antecedentes normativos; o acordo entre as partes como primeira condição de procedimento; as condições referidas no cân. 1683,2; a disparidade dos exemplos de acordo com as Normae art. 14 e a analogia com o pressuposto do processo documental; a fase inicial do processo mais

\section{Manuel Jesús Arroba Conde ${ }^{2}$}

1 Sexta conferência proferida no II ${ }^{\circ}$ Simpósio Canônico "Questões seletas de Direito Matrimonial e Penal Canônico", promovido pelo Instituto Superior de Direito Canônico Santa Catarina em 8-9 de maio de 2018.

2 Doutor, Professor e Presidente do Institutum Utriusque Iuris da Pontificia Universidade Lateranense de Roma. Recentes publicações do autor sobre o tema da conferência: Il m.p. Mitis Iudex Dominus Jesus in relazione al concetto di giusto processo, in Arcisodalizio della curia romana, Quaestiones selectae in re matrimoniali ac processuali, Città del Vaticano 2018, pp. 9-34; La disciplina sobre el nuevo proceso brevior in SADEC, XV Jornadas anuales, Buenos Aires 2018, pp. 191- 228; com C. IZZI, Pastorale giudiziaria e prassi processuale nelle cause di nullità del matrimonio dopo la riforma operata con il Motu proprio Mitis Iudex Dominus Iesus, Cinisello Balsamo 2017, 320 pp; El proceso más breve ante el Obispo, en L. Ruano - C. Guzmán (Edd.), Reforma de los procesos de nulidad y otras novedades legislativas de derecho canónico y eclesiástico del Estado, Madrid 2017, 249-278; La procedura extragiudiziale per la dichiarazione di nullità del matrimonio, Gruppo Italiano docenti diritto canonico (ed.), Il diritto nel mistero della Chiesa, IV, Città del Vaticano 2014, 173-186; sub cc. 1671-1691, en A. Benlloch Poveda (ed.), Código de derecho canónico. Edición bilingüe, fuentes y comentarios de todos los cánones, Valencia (16a ed.) 2016, 722-738; La interpretación de las normas del MIDI sobre la apelación y la ejecutividad de las sentencias, in L. Ruano Espina - A. M. López Medina, Antropología cristiana y derechos fundamentales. Algunos desafios del siglo XXI al derecho canónico y eclesiástico del Estado, Madrid 2018, pp. 349-377. 
breve; a fase probatória no processo mais breve; a decisão e as impugnações.

Palavras-chave: Processo mais breve. Processo documental. Fase probatória. Decisão. Impugnação. of the procedure; the probationary phase in the shortest possible procedure; the decision and the impugnation.

Keywords: Briefer process. Documentary process. Probative phase. Decision. Impugnation.

\section{Introdução}

$\mathrm{O}$ art. 5 do m.p Mitis Iudex (cânn. 1683-1687; cfr. Proemio IV e Normae artt. 14-20) contém a parte que pode ser considerada a maior e, aparentemente, a mais inovadora da reforma. Se digo aparentemente é por duas razões: em primeiro lugar, porque existem normas extracodiciais (como a Lex propria da Assinatura, e certas faculdades especiais concedidas para o território da China pela Congregação para a Evangelização dos Povos) que de algum modo, antecipam elementos desta reforma, ao menos parcialmente; em segundo lugar, porque a parte mais longa, objeto da mais incisiva renovação e da mais frequente aplicação, permanece, no meu ponto de vista (também para este processo breve) aquela inerente a preparação da causa.

\section{A denominação do processo em relação à sua natureza}

Não me parece adequada a denominação dada ao processo (Processus brevior coram Episcopo) porque, na minha opinião, pode ser un desvio, em relação aos elementos irrenunciáveis do processo, como se o valor essencial fosse a rapidez no decidir. Tal risco se concretiza sobretudo com um significado superficial as palavras, como acontece frequentemente entre os não juristas, que se improvisaram comentadores do novo procedimento.

A previsão deste procedimento obedece a uma das propostas emergidas diretamente na sala sinodal, por esta razão não presente no instrumentum laboris da assembleia de 2014, mas que encontrou logo bom acolhimento, sendo indicada seja no texto da Relatio postdisceptationem seja naquele conclusivo da Relatio Synodi. Naquela proposta (como referi nas minhas publicações antecedentes ao motu proprio) este gênero de processo foi mais adequadamente denominado 
"processo judiciário extraordinário", seja para salientar que se trata de um processo excepcional, seja sobretudo porque a sua aceitação teria representado (como de fato aconteceu) a superação da mais insidiosa ideia, que a meu ponto de vista, pesava sobre a reflexão sinodal a cerca desta matéria: refiro-me as propostas do qual o nó central era constituído pelo objetivo de não confiar mais ao discernimento judiciário as nulidades do matrimônio, preferindo como alternativa um juízo de foro interno (nunca passando pelas testemunhas, não obstante a reavaliação das convicções de consciências das partes) ou um processo de caráter adiministrativo, com um procedimento sem regras préestabelecidas ou com regras muito genéricas, entregues para a sua concretização a mesma autoridade decisória (cân. 50).

A proposta de um processo judicial extraordinário respondia também ao fato de não se acomodar na avaliação de duras críticas contra a atividade dos tribunais, com o lamento (embora fundado) sobre a falta de pessoal, ou ao menos, de pessoal preparado e atualizado, sustentando que as reais inadequações da praxe não dependiam realmente de uma presumível inadequação das regras, mas das pessoas, incluindo tantos bispos que não tinham investidos suficientemente na preparação, atualização e na destinação a este serviço, operadores (clérigos e leigos) suficientes. Limitar-se unicamente a reações de críticas, admitindo eventualmente que podiam ser feitos alguns retoques técnicos (também significativos, como a eliminação de duas decisões conforme ou outras), teria provocado o risco de que fosse compreendido a defesa da lei processual como algo quase inalcançável, e a defesa dela como uma posição imobilista.

Por outro lado, sublinhar somente a falta de pessoal ou a falta de responsabilidade da parte dos bispos no enviar pessoas a prepararemse, clérigos ou leigos, poderia estimular, por sua vez, que os bispos confirmassem a impossibilidade real de superar tais inconvenientes, e, portanto, a necessidade de resolver diferentemente, isto é, assumindo eles mesmos as causas por via administrativa. Como frequentemente acontece, tais soluções seria um meio de resolver o problema, ignorando-o. Querendo evitar tais tentações, era necessário propor uma reforma que não se limitasse somente em "reduzir" a um o procedimento de averiguação (como acontece com a supressão da dupla confor- 
me), mas que tivesse uma incidência no procedimento, ao passo que, fosse judicial e conduzida pela estrutura judicial.

Em tal sentido, embora não gostando da denominação atribuída no motu proprio, sinto-me no dever de encorajar a receber também este aspecto da reforma com a maior confiança possivel, porque de fato representa um gesto de confiança do sínodo em nós, operadores das estruturas judiciárias, não obstante possa parecer o contrário, considerada a modalidade concreta, com a qual foi predisposto pela comissão a questão da decisão final (modalidade que podia ter sido diversa); mesmo se a decisão é confiada ao bispo, o procedimento é de qualquer forma judicial, conduzido pelos serviços judiciais com preparação técnica (o vigário judicial pela admissão; o instrutor pela fase probatória), e obrigando ao bispo a levar em consideração os pareceres técnicos (do instrutor e de um assessor).

\section{Antecedentes normativos}

Propondo este processo, demonstrava-se que, também a luz de normas extra-codiciais antecedentes, era possivel prover a uma reforma de lei mais radical, mesmo se para aplicar em via muito excepcional (extraordinária). Os antecedentes normativos aos quais se podia referir e, em um certo sentido inspirar parcialmente, são dois: o mais próximo obviamente é aquele representado pelo artigo 118 da Lex propria da Assinatura que, como sabeis, confia ao supremo tribunal (com um decreto do prefeito depois da discussão em Congresso) de declarar as nulidades do matrimônio em casos que não exijam outras averiguações. É verdade que se trata de uma decisão estabelecida com decreto extrajudicial do prefeito, consequentemente, não de sentença; o exame vem feito em Congresso com intervento do defensor do vínculo, não das partes, naquela fase, supondo-se que estes já tenham intervindo antes. Se trata, portanto, de um precedente normativo análogo, não porém idêntico, se bem que o pressuposto seja idêntico àquele que hoje se prevê nos processos entregues aos bispos: isto é, que os dados existentes antes de decidir, já em poder da Assinatura, tenham um nível de averiguação tão alto de não exigir que se faça um processo judicial ordinário. Estes dados chegam a Assinatura, enviados pelas 
Igrejas locais privadas de estruturas, portanto impedidas de realizar investigações judiciais, mas sem retirar a essência do juízo, enquanto os dados são recolhidos de maneira tal, que sejam suficientes para tornar manifesta a nulidade: o texto do art. 118 diz, realmente, que não exijam posteriores investigações.

A doutrina interpretou sempre o fato de "não exigir posteriores investigações" não em sentido absoluto, mas circunscrito, isto é, que possa ser suficiente uma pesquisa baseada somente na comprovação e ratifica do dado histórico principal (do fato jurídico gerador da nulidade), enquanto os outros dados históricos indiretos adquiridos in limine litis resultem certos, embora provisoriamente. Mais precisamente, a doutrina (em primeiro lugar, Grocholewski, seguido em tais interpretações Burke e por mim) afirma que o fato de "não exigir posteriores investigações" significa em realidade "não exigir uma investigação tão apurada, articulada nas suas fases e completas nas suas solenidades como aquela que se realiza em um juízo ordinário"; este endereço doutrinal, a meu ver, resulta também chave para interpretar o novo procedimento mais breve diante do bispo.

Temos outro precedente normativo no CIC, mesmo se este é, provavelmente mais distante: refiro-me a norma que reconhece a legitimação de agir do promotor de Justiça, nos casos em que exista uma notória nulidade do matrimônio e, por sua vez, não seja possivel ou conveniente convalidar o matrimônio. Habilitar a exercitar a ação à parte pública pela notoriedade dos motivos de nulidade, realmente, porque se trata somente de iniciar a causa ordinária, não é, portanto, comparável completamente ao conceito atual de nulidade manifesta; isto que agora consente, este último conceito vai muito além: circunscrever a prova e, em força disto, consentir um processo não ordinário. Se trata seja como for de normas (o art. 118 da Lex Propria) e conceitos (aqueles de nulidade divulgada do cân. $1674 \S 1,2$ e de nulidade manifesta, do novo cân. 1683,2) muito próximos, ao menos para poder alegar estes dois antecedentes e sustentar a possibilidade de modificar a lei vigente ampliando a aplicação com pressupostos e possibilidades análogas.

Do ponto de vista estritamente processual, o antecedente mais pertinente é reconduzível às normas do processo documental, também 
ele, processo sumário, mas limitado, no que diz respeito aos meios de prova (somente a documental) da qual se deduz in limine litis a nulidade. No Sínodo se propôs que fosse de qualquer modo, o tribunal, não somente a tratar, mas também a decidir, certamente em maneira mais rápida, exatamente de maneira análoga a via documental. $\mathrm{O}$ bispo, na proposta sinodal, teria tido somente o dever de autorizar este processo judicial extraordinário, depois de uma informação ou um parecer expresso do promotor de justiça, fundado nos dados retirados da preparação da causa. Uma denominação, portanto, diversa, uma intervenção análoga àquela que já hoje se prevê sobre a base da pastoral judicial prévia à causa, uma decisão do bispo, mas somente sobre a possibilidade pendente de seguir esta via.

$O$ fato que no percurso da elaboração da norma tenha sido alcançado a outras disposições no que diz respeito a este gênero de causa, isto é, que não seja o promotor de justiça, mas o vigário judicial a avaliar a possibilidade de percorrer esta via extraordinária, que seja $o$ mesmo vigário e não o bispo a consenti-la nos casos particulares, acredito que seja uma questão de menor peso, que provavelmente responde as carências de pessoal. Se preferiu, além disso, que o envolvimento do bispo no que se refere as decisões e somente as decisões sobre o mérito, garantindo, assim, o seu envolvimento direto, mas evitando que este tenha por objeto os aspectos, talvez menos essenciais (em sentido substancial), mas por certo, mais difícil do ponto de vista técnico, como são as avaliações prévias das condições do proceder e, sobretudo, a gestão do proprio processo e das suas, embora sucintas, solenidades.

\section{O acordo entre as partes como primeira condição de procedi- mento}

As condições para proceder são cinco, reagrupadas nos dois parágrafos do cân. 1683. Sobre estas condições convém por um momento refletir com modéstia, enquanto o colocar em prática desta normativa, poderá apresentar problemas e soluções que, nesta fase da reflexão doutrinal, são ainda pouco claras, e não convém resolver com novas disposições positivas. Para mim a norma parece suficientemente bem- 
feita, ao menos para evitar que existam dúvidas sobre o fato, já que se trata de uma via de processo extraordinário.

O primeiro requisito é o litisconsortio ativo das partes. $\mathrm{Na}$ averiguação prévia o advogado cumpre um papel especial, de tudo insubstituível em vista de alcançar este importante resultado. O motu proprio confirma indiretamente que seja deontológicamente correto estabelecer contatos com a outra parte na fase prévia da introdução da causa; da minha parte, tenho sempre sustentado esta possibilidade riferindo-me aos aspectos específicos da deontologia forense canônica. Obviamente não se trata de contactar ambas as partes e de obter o seu acordo sobre a base de uma reconstrução forçada dos fatos, em sentido não verídico: o objetivo deste contato é informar a parte que não tinha a primeira iniciativa e conhecer a sua posição no mérito.

No informar se deve fazer compreender a natureza declarativa da causa, e de evitar inutéis conflitos entre as pessoas como se o objeto da causa, em lugar de clariar uma dúvida sobre a validade do matrimônio, considerasse a certeza comportamental, ética ou moral de um e de outro cônjuge. A informação à outra parte servirá, em todo caso, para advertir da importância que reveste o participar ao processo e oferecer a própria versão dos fatos. Por tais razões o contato prévio é um recurso fundamental de pastoral judicial, independentemente do fato que desfoquem, em seguida, numa lide consórcio ativa inicial; sobre o ponto da deontologia canônica apareceria afastar-se daquelas habituais, na justiça secular; em realidade os códigos deontológico dos colégios profissionais forenses proíbem o contato com a outra parte se com ele se transgride ao dever de coleguismo (de advertência entre os advogados); isto significa que não é consentido o contato com a outra parte, mas somente quando esta seja assistida de seu próprio advogado.

Qual é o objeto da litis consortio? Se pode pensar que o objeto seja somente o petitum, a saber, obter a nulidade do matrimônio, independentemente, do motivo adotado, não encontrando aquilo que possa ser obstáculo para poder seguir a via breve, o fato é, que sobre o motivo de nulidade as partes tenham posições contrastantes. Se pode pensar que, além do petitum, o acordo deva alcançar a causa petendi, ou seja, é necessário que as partes concordem sobre o motivo de nulidade 
adotado, ao menos em termos jurídicos, independentemente dos fatos sobre os dados históricos, nos quais se fundam o referido motivo, e as partes deem versões diversas. Uma terceira posição seria dada, por acreditar necessário, que as partes sejam de acordo sobre os fatos históricos postos a fundamento do motivo de nulidade. Posterior interpretação é aquela de acreditar que o acordo entre as partes deva verter também sobre o pedido de seguir a via processual mais breve; que é, ao invés, somente este elemento processual o objeto do acordo, parece francamente pouco adequado com a segunda condição, da qual nos ocupamos a seguir.

Não podemos negar, seja como for, que considerar como objeto do acordo entre as partes somente a questão da via processual a seguir, teria duas vantagens, em linha teórica. A primeira, aquela de fazer pensar que a questão de mérito (da nulidade do matrimônio) possa depender diretamente do fato que as partes sejam de acordo, em uma espécie de decisão consensual, como acontece em tantas legislações modernas em matéria matrimonial (de separação e divórcio); que a coincidência entre as partes torne mais fácil a verificação, como é obvio, não significa que a averiguação possa ser confiada somente às partes ou depender unicamente da sua exclusiva contribuição. Uma segunda vantagem concerne ao modo de enfrentar as atribuições reconhecidas ao vigário judicial, que compreende a possibilidade de originar um processo breve para a causa iniciada pelo demandante sem pedir tal via processual, atendo-se, portanto, às normas do processo ordinário.

Consideramos, todavia, que, além da litisconsortio ativa, inicial entre as partes (ou seja, o litisconsortio em sentido próprio), a norma prevê que este primeiro requisito possa ser configurado como litisconsortio sucessivo, a saber, que é depois da citação do vigário judicial no momento de aceitar um libelo apresentado pelo demandante para seguir a via ordinária. Se prevê realmente a litisconsortio em sentido impróprio e, isto é, o mero consenso de uma parte à iniciativa judicial da outra, mas permanecendo esta última como única parte que assume o papel de demandante. $\mathrm{O}$ demandado porém deve ser ajudado a isto; além do decreto de citação (que deve ser límpido na sua natureza jurídica de "comando de resposta"), um formulário ou documento anexa- 
do, de natureza mais pastoral, que serve a explicar o significado do processo e das várias alternativas de resposta que estão a disposição do demandado (se esta informação não foi feita em fase de preparação).

Um ponto potencialmente problemático refere-se ao que seria representado pelo eventual desacordo a respeito da decisão do vigário judicial. Se poderia dizer que, independentemente de quanto seja correto considerar que ao demandante (em força do principio dispositivo) pertença a capacidade de estabelecer que o procedimento seja aquele ordinário, o necessário acordo entre as partes envolve também a ele, obviamente, pelo qual, se não fosse de acordo com a decisão de provir a causa ao procedimento breve (por quanto possa resultar paradoxal que um autor não queira ter tais aparentes vantagens processuais) $o$ vigário judicial não deve dispô-la, em força da ausência do primeiro requisito de procedimento.

Um segundo ponto problemático a respeito do acordo entre as partes se refere ao eventual desacordo que possa verificar-se no decorrer do processo. Em tais casos necessitaria distinguir bem o objeto real do desacordo, isto é, se o petitum, se os motivos de nulidade, se os fatos ou, de novo, somente o procedimento. Uma questão certa é que nos exigirá também muita clareza no distinguir o momento em qual emerge o desacordo: se depois da litis contestatio, mas ainda em tempo útil para sua impugnação; se só sucessivamente, antes ou depois do início da fase instrutória, ou logo depois da conclusão desta;... Em todos estes casos, se bem que em maneira diversa, pode ser posta em perigo o pressuposto essencial da nulidade manifesta. Se estabelecer o procedimento mais breve compete ao vigário judicial no decreto com o qual fixa a dúvida, um posterior reenvio ao processo ordinário é disciplinado diretamente somente como decisão que cabe ao bispo no momento do pronunciamento conclusivo (cân. 1687 par. 1). O princípio do justo processo e o valor do contraditório, junto a economia processual, sugerem de poder enfrentar esta eventualidade, segundo a disciplina prevista pela modificação dos termos da controvérsia, da qual o cân. 1514, fazendo uso das exceções processuais que possam, nos casos particulares, resultar mais pertinente, sem excluir a eventual renúncia, se as circunstâncias o consentem. 


\section{As condições referidas no cân. 1683,2}

A esta primeira condição se acrescentam outras quatro, expressas de acordo ao número do cânon. Tal número encerra os aspectos que possam ser considerados mais insidiosos. Acredito interessante a sugestão de modificar a ordem em qual resultam escritas estas quatro condições, colocando ao segundo lugar aquela condição que resulta indicada como terceira; a mudança pode facilitar a compreensão do conceito mais delicado, a saber, que a nulidade antes de iniciar o processo possa resultar manifesta; este resultado é a ultima das quatro condições, indicadas no segundo número do cânon e, obviamente, se deve considerar que se faz depender da existência das outras três, ou seja, que recorram a circunstâncias de fatos ou de pessoas (primeira condição), que não exijam posteriores averiguações (terceira condição), sustentada pelos testemunhos ou documentos (segunda condição).

Uma vez que as circunstâncias por si só, quais fatos históricos indiretos, não são manifestações plena, automática e de tudo moralmente certa do fato principal, que gera a nulidade matrimonial (como se deduz pelo elenco exemplificativo indicado no art.14 das normas processuais), o suporte das testemunhas ou dos documentos deve entender-se como referido sobretudo a este seguinte elemento, a saber, a ligação entre as circunstâncias, certas e não necessitadas de posteriores provas, e o concreto motivo de nulidade do qual as circunstâncias serão somente indício ou subsídio.

Se esta leitura resulta correta se compreende melhor o motivo pelo qual esta via processual possa resultar mais breve: porque a investigação, através dos testemunhos ou documentos, poderá ser circunscrita a verificar exclusivamente o efetivo nexo, no caso concreto, entre as circunstâncias certas e já conhecidas e o fato principal adotado como princípio de nulidade. Raciocinando em termos negativos, se deve considerar que o objeto de tal investigação circunscrita deva de qualquer modo incluir tudo que sirva para assegurar-se que aquelas circunstâncias certas, que induziram a seguir a via processual mais breve, não sejam verificadas por razões ou fatores que nada tenham 
que ver com o motivo de nulidade, como poderiam ser aquelas referentes as imperfeições da vida conjugal.

Creio também que esta interpretação possa ajudar a avaliar em termos mais equilibrados, por quanto possam ser parecidos com aquelas utilizadas em alguns dos primeiros comentários, o elenco de circunstâncias exemplificativas indicadas no art.14 das normas processuais: não obstante, não seja técnica habitual, considero excessivo arrancar-se as vestes porque uma norma se exprime em termos exemplificativos e conclua com um "etc". Se aplicarmos a interpretação precedente a uma das circunstâncias indicadas nas normas, talvez apareça mais claro, o exato significado da maior brevidade, que possa ter o recurso a esta via judicial extraordinária. Pense, por exemplo, a interrupção repetida das gestações intercorridas no curso da união, alegando-se como motivo de nulidade a exclusão da prole por parte da mulher, de qual tais abortos se apresentam como indício. O processo breve poderá ser feito quando sobre esta circunstância, antes do processo, além de uma versão coincidente das partes, hajam certezas documentais ou testemunhais tais, de não dever mais indagar sobre a existência dela nos modos como se faz no processo judicial ordinário; então, o processo terá como único objeto instrutório o exame das partes e das testemunhas a cerca dos motivos de tais e de tal comportamento pósnupcial, de modo, a compreender se obedece a uma recusa pré-nupcial da prole e que não tenha sido, ao contrário, motivado por razões de outro genêro, sucessivas ao matrimônio.

\section{A disparidade dos exemplos de acordo com as Normae art. 14 e a analogia com o pressuposto do processo documental}

Não obstante a ajuda que possa derivar pela mudança de "condições" apenas referida, não se pode, não fazer notar que tal sugestão apareça menos adequada no que diz respeito a alguns dos exemplos indicados nas Normae art. 14. Com efeito, alguns deles não são estritamente circunstâncias, factuais ou pessoais, mas exprimem diretamente e unicamente o fato jurídico gerador da nulidade. Tal é o caso da "violência física para extorquir o consenso" diretamente estabelecido no cân. 1103; em outros casos no exemplo, se acrescenta ao fato 
jurídico uma circunstância de prova, como no caso da "falta de uso de razão" prevista qua talis no cân. 1095,1, acrescentando que a evidência se dá se esta carência é "comprovada por documentos médicos". Em outros casos, o exemplo se relaciona a uma prova indireta, comumente reconhecida pela jurisprudência em relação a um capítulo de nulidade, como acontece respeito ao dolo sobre a esterilidade, sobre doenças contagiosas, sobre filhos precedentes, ou a respeito da simulação total, pelo fato que tenha sido causa das núpcias uma razão de tudo estranha ao matrimônio, ou a respeito da exclusão da fidelidade, pela existência de uma relação extraconjugal continuada em um tempo, próximo a celebração. Em outros casos, o exemplo tem por objeto somente condições de fato muito relevantes, mas pelas quais é difícil sustentar que por si só sejam manifestações de uma nulidade evidente, exigindo-se outros elementos (inicialmente se presume que menos claros) para poder obter tal conclusão; tal é o caso da falta de fé, da qual se diz que pode gerar simulação ou erro, determinando a vontade.

Mais bem-sucedidas, me parecem os exemplos acerca da exclusão da prole, manifestadamente dedutível (embora não incontestável) pelo fato de ter impedido a procriação, provocando o aborto; sobre a possível exclusão da indissolubilidade, do mesmo modo dedutível pela brevidade da convivência, ou sobre a simulação total ou defeito de liberdade, dedutível pelo fato que o matrimônio tenha sido causado pela gravidez imprevista da mulher.

É interessante fazer notar a grande semelhança entre o processo documental do código vigente com o novo procedimento judicial extraordinário que resulta ser o processo mais breve, estabelecido no motu proprio. Em ambos os casos, existe antes do processo um nível de averiguação dos fatos adotados mais elevado daquilo que é habitual; uma investigação que consente a circunscrever a atividade processual sucessiva na efetiva comprovação do contraditório de poucos elementos, com impossibilidade de decidir negativamente, consentindo-se somente o reenvio a exame judicial ordinário. Trata-se de semelhança e não de identidade, enquanto no processo documental, o reenvio a exame judicial ordinário é destinado sempre ao tribunal de primeira instância; enquanto no novo processo mais breve o reenvio se prevê também em grau de apelo e destinado ao tribunal de segunda 
instância. É importante notar sobretudo a comum natureza judicial de ambos, nos tipos de procedimento, não obstante tenham um objeto de averiguação mais limitado.

Além das circunstâncias indicadas a título exemplificativo do artigo 14 das normas processuais, que se referem, sobretudo, ao direito substancial, podem ser indicadas ainda outras de natureza também processual. Em primeiro lugar, aquelas circunstâncias indicadas na doutrina dos diversos anos, para propor a extensão do processo documental, também a fattispecie não se referindo a um impedimento não dispensado ou um defeito de forma não sanado; entre estas se falava dos casos no qual exista documentação clínica relativa a uma patologia psíquica, que pela sua natureza não possa, não tenha já estado presente no tempo das núpcias, e que possa ser relevante em relação as fattispecie do cân. 1095,2-3. Não poderia, ao contrário, utilizar-se esta via processual mais breve para os casos em qual a situação psíquica sejam as anomalias mais breves e leves, que exijam maior investigação sobre a sua relevância jurídica. Outras circunstâncias de natureza processual que poderiam induzir a servir-se do processo judicial extraordinário mais breve, enquanto consentem de basear a sucessiva investigação sobre poucos elementos, pode ser o reconhecimento prévio ao processo, por parte do protagonista do motivo de nulidade: pense, por exemplo, a um confiável reconhecimento do próprio comportamento coativo por parte de quem foi o autor do temor nos casos de metus (e não somente de violência física). Outra circunstância pode ser o testemunho profissionalmente qualificado daquele que acompanhou os cônjuges no momento da crise e pela qual se deduza a existência de uma situação física ou psíquica, suficientemente, contundente e por sua natureza prévia as núpcias em uma ou em ambas as partes.

\section{A fase inicial do processo mais breve}

O libelo do processo mais breve não deve ser como o libelo do processo ordinário, enquanto dele devem emergir outros elementos para se avaliar a possibilidade de ser seguida esta via processual. Assim, no libelo do processo ordinário é suficiente indicar os fatos generatim saltem; ao invés disso, é muito conveniente esta exposição só- 
bria, também por não comprometer a participação adequada e verídica da outra parte, protagonista do processo. No processo mais breve, mesmo porque tem como primeiro pressuposto a obrigatória versão coincidente das partes sobre os fatos apresentados, o libelo deve conter a exposição integral destes (e não generatim). Deve além disso, indicar as provas que podem ser imediatamente recolhidas; isto significa referir-se aqueles testemunhos que possam sustentar e ratificar a certeza provisória que permite o utilizo desta via. Não basta, por isso, enfrentar o tema do fumus bonis iuris nos termos minimamente estabelecidos pelo cân. 1505; é necessário também indicar as provas para obter em termos mais precisos e completos, o que sugere a teoria da substanciação e não aquela da mera individuação.

$\mathrm{O}$ que foi dito refere-se certamente ao caso, em qual o processo breve vem requerido pela parte demandante em litisconsórcio com a demandada ou ao menos com o consenso prévio desta. Na outra hipótese, ou seja, quando o demandante não tenha pedido de seguir a via mais breve, e seja o vigário judicial a decidir de reconduzir a ela $o$ processo, depois de ter avaliado o teor concordante e coincidente da resposta do demandado à citação, não creio que se possam estabelecer hipóteses muito diferentes sobre o conteúdo do libelo, que se deve alegar na citação. É embora verdadeiro que, ao menos em teoria, existem dois tipos de situações que poderiam ter sido motivadas com a decisão do vigário judicial: aquela na qual o demandante simplesmente, não se colocou em contato com a parte demandada antes de apresentar o libelo, ou não conseguiu, de qualquer modo, o seu consenso formal a apresentação dele; aquela na qual, a resposta do demandado à citação, não somente seja coincidente respeito ao que foi dito no libelo e concordante com a iniciativa judicial do demandante, mas contenha outros elementos não presentes no libelo, tornando o quadro dos fatos mais completo, até satisfazer aos outros requisitos exigidos, para que a nulidade se possa considerar manifestada, e suscetível de averiguação pela via mais breve.

O eventual silêncio da parte demandante à citação, a qual se faz referimento no número 11 das normas processuais, interpretando-o como não oposição à causa, não é possivel considerá-lo, como base suficiente para utilizar-se do procedimento mais breve; para esta se 
requer, de fato, um verdadeiro consenso explícito de ambas as partes, requisito que não pode ser considerado satisfeito com apenas o silêncio da parte, não obstante se o interprete como uma não oposição. Em realidade, tal não oposição deve ser interpretada com cautela: a não resposta do demandado não tem como efeito a aceitação da versão dos fatos dada pelo demandante, mas que não poderá impedir que a versão da parte demandante seja a base da inteira atividade probatória. Esta é a razão pelo qual tenho sempre insistido sobre o fato da necessidade de ajudar a parte demandada a compreender que o seu silêncio à citação, a sua sucessiva não participação ao processo, assim como uma participação meramente superficial, voltada exclusivamente a negar as afirmações do demandante em maneira apodítica, não são estratégias em grau de impedir totalmente os direitos do demandante, cuja versão terminará por ser aquela que orientará a inteira versão probatória.

É interessante que no motu proprio não se faça menção do defensor do vínculo na fase de admissão do pedido (cân. 1685), mas é obvio que, o pressuposto do acordo entre as partes, fará resultar o defensor do vinculo como única parte em eventual oposição, ao menos no procedimento mais breve, pelo qual deverá ser citado e na sua resposta à citação poderá indicar o quanto considera oportuno, ser contra a possibilidade de continuar a via mais breve.

É interessante também que não se preveja como sujeito do litisconsórcio (que pode consentir a tramitação da causa por via mais breve) a legitimação ativa do promotor de justiça. É interessante tal silêncio, se se tem presente que o requisito ao qual o ordenamento canônico confia ao promotor de justiça da ação de nulidade, é aquele que se trata como nulidade notória e não seja possível ou conveniente convalidar o matrimônio. Considero que a não menção do promotor de justiça como parte que possa ser sujeito do acordo próprio ou impróprio do litisconsórcio, responda ao fato que a parte pública seja somente sujeito da ação, mas não sujeito da lide, portanto, não é protagonista dos fatos que devem ser investigados; se assim fosse, o fato ao qual não se inclua ao promotor entre os sujeitos do litisconsórcio reforça a interpretação, segundo a qual, o objeto do acordo entre as partes são também os fatos históricos sobre os quais se funda o pedido de nulidade. 
Que o acordo entre as partes deva verter sobre os fatos, parece necessário também por outra razão. Refiro-me ao papel do bispo, ao qual se entrega a decisão. O bispo além de juiz próprio é também e, sobretudo pastor; não se pode comprometer por uma questão de procedimento esta função mais vasta, pela qual deriva que cada uma das partes possa ter no bispo um ponto de referência; tal possibilidade seria muito comprometida se o bispo mesmo devesse decidir sobre fatos a respeito dos quais as partes mantenham versões reciprocamente contrastantes.

\section{A fase probatória no processo mais breve}

Sobre o fato que a prova possa ser, assim, reduzida ao nexo entre as circunstâncias certas e o motivo de nulidade alegado, creio que as normas, onde se estabelece o ideal de uma única sessão de instrutória, devem ser completadas, incluindo o envolvimento direto das partes, aos quais necessita pedir o empenho de tomar medidas, enquanto possível, a fim de que as testemunhas por elas sinalizadas participem efetivamente na audiência fixada a necessidade, por parte do Vigário judicial. É ao Vigário que cabe, de fato, no mesmo decreto com o qual estabelece a dúvida e ordena de continuar a via judicial mais breve, designar o instrutor e o assessor que intervirão no aconselhar o bispo diocesano que deverá decidir a causa, e convocar os interessados para a sessão da instrutória, advertindo que três dias antes da data estabelecida, possam ser completadas as provas propostas, seja acrescentando nomes que, sobretudo, determinando melhor com as perguntas, os únicos elementos da investigação circunscrita.

Em tal sentido, considero útil exprimir como objeto posterior deste polivalente decreto, na parte dedicada à citação para a sessão instrutória, uma exortação às partes, entregando a elas o cuidado de quanto necessário para que a aquisição da prova se possa realizar na data estabelecida pelo vigário judicial. A data, por sua vez, deverá ser combinada com quem em seguida desenvolverá a instrução.

A questão da apelabilidade do decreto do vigário judicial por parte dos cônjuges, quando decide de reconduzir uma causa ao processo breve, é uma hipótese não combinável com o pressuposto pri- 
meiro destes tipos de processos, ou seja, com o acordo das partes privadas; é, portanto, racional pensar que a única parte que poderia recorrer contra esta decisão é o defensor do vínculo. Trata-se, porém, de decisões interlocutórias sem força de sentença definitiva, e não priva do direito ao processo judicial, através do qual não aparece possível considerar que seja passível de recurso. Não parece de tudo incoerente sustentar que, dada a coincidência material (em um mesmo decreto) da decisão inerente a fixação da dúvida e aquela referente ao procedimento a seguir, se possa estender a esta última a faculdade de expedir o recurso, dentro de dez dias, certamente, consentido a respeito a dúvida. Em todo caso, a sucessiva decisão (seja porque o cân. 1513 estabelece-a como expeditissime, seja porque meramente interlocutória) não é posteriormente recorrível como não o é (pelos mesmos motivos) $\mathrm{o}$ decreto com o qual o vigário judicial recusa o pedido de seguir $\mathrm{o}$ processo breve, e ordena que a causa seja tratada pela via judicial ordinária; em realidade esta eventualidade (a diferença de quanto acontece com a conversão em processo breve de um processo iniciado como ordinário) não é expressamente prevista; considero obvio que a eventualidade seja compreendida na norma que atribui ao vigário judicial decidir a via a seguir (cân.1676 §1); assim, no examinar o pedido, poderá constatar a falta de requisitos para o procedimento breve e decidir que se proceda pela via ordinária.

Sobre o desenvolvimento da audiência para a instrutória, o elemento mais distante do procedimento matrimonial até agora existente é a presença das partes, prevista no código somente para o processo oral. Poderia atingir esta circunstância, visto que o motu proprio não deixa de repetir a proibição de tratar oralmente estas causas, nem pela via mais breve. É licito pensar que o motivo de tal presença seja uma ulterior manifestação da centralidade que possuem os fatos históricos, que é objeto da coincidência entre as partes, acima da concordância somente sobre o petitum ou sobre a causa petendi na sua dimensão jurídica só formal; a presença deles nas recíprocas declarações, permite de entender melhor se de fato sustentam uma mesma versão a cerca dos fatos, que contam, com o objetivo da declaração de nulidade matrimonial. Sobretudo, quando o acordo entre as partes não tenha sido inicial, mas sucessivo à primeira citação, creio que a instrutória deva 
iniciar com o interrogatório da parte demandada. Fazendo-lhe ver também eventuais documentos que não tenham sido notificados com a citação.

Considero que nestas causas a figura do instrutor deva ser desenvolvida por um juiz e não por um auditor, como se consente no código (cân. 1428) para recolher as provas em todo tipo de processo, sem distinção. O motu proprio não faz menção do auditor, mas somente do instrutor, e estes na prática (mas não por derivação de uma norma geral clara) é uma qualificação reservada aos casos em que a instrutória é conduzida por pessoas, que ocupam o ofício de juiz. Neste caso, convêm que não se permaneça na incerteza, satisfazendo-se de uma interpretação derivante só da prática, já que os outros que intervêm no juízo de mérito, como são o assessor e o bispo, como único juiz, poderiam ser carentes da devida perícia canônica e dos títulos que se exigem que devam possuir os juízes (doutorado ou ao menos licença em direito canônico). No meu ponto de vista, também o assessor que intervém no processo mais breve deveria ser escolhido entre os juízes. Na posse, portanto, do título.

Nas Normae processuais (art. 18 §) se estabelece que, na sessão instrutória, o notário faça uma redação sóbria, limitada aos fatos substanciais. Trata-se de uma regra que deveria valer para todo tipo de causa e de via processual, se bem que as normas ordinárias sobre o exame das partes, das testemunhas e dos peritos dispõem que o notário indique no depoimento toda circunstância da audiência instrutória digna de nota. Creio que o encaminhamento sóbrio possa valer também no caso em que as partes não estejam presentes à sessão, não obstante a faculdade que habitualmente assiste a eles, mas que o juiz poderia limitar por circunstância de pessoas ou de coisas (Normae art. 18 $\S 1$ ); se não são presentes é claro que a sobriedade da redação não poderá comprometer o direito à sua informação (como dimensão do direito à defesa), espera que não é prevista (provavelmente para a sua faculdade de ser presente no recolhimento das provas) a formal publicação dos autos, o decreto de conclusão in causa, nem uma fase de discussão verdadeira e própria, como acontece nos processos documentais. 
Em realidade, sendo reconhecida a faculdade das partes ou dos seus defensores de apresentar dentro de quinze dias eventuais observações (que são ao invés, obrigatórias para o defensor do vinculo, cân. 1686), considero que, embora com solenidade diversa, seja necessário tutelar os direitos processuais, mas de natureza também substancial, protegidas com os atos processuais não previstos neste específico procedimento, além disso, outros valores igualmente anexos a estas solenidades. Refiro-me ao direito a ter cópia tempestiva dos autos, que assiste à parte pública e aos advogados, para poder expor adequadamente os argumentos na defesa da respectiva posição processual; refirome também ao reconhecimento às partes da possibilidade de tomar conhecimento dos autos, se não foram presentes a instrutória; o valor da rapidez, não obstante a expressa proibição de proceder oralmente (segundo os cânn. 1656-1670) nas causas de nulidade matrimonial (cân. $1602 \S 1$ ) de substituir as defesas escritas por uma exposição oral no dia da decisão; contrariamente, a mesma rapidez leva a pensar que não se devam considerar direitos protegidos, nesta via processual extraordinária, a réplica às argumentações e observações dos outros.

\section{A decisão e as impugnações}

A decisão foi entregue ao bispo, dizendo-se expressamente no Proêmio que isto obedece a exigência de evitar o laxismo, por causa da rapidez deste processo. Em tal sentido, creio que não seja simples afirmar a delegabilidade deste dever: ao bispo não se lhe entrega uma causa, mas somente a decisão. Além da idêntica natureza episcopal na qual se funda o poder judicial do papa (que é delegável), a doutrina tradicional indica três razões para considerar delegável o poder do bispo nos casos em qual, para as circunstâncias, se viesse constrangido a exercitá-la pessoalmente: pelo tempo que exige o processo; pela sua pessoal imperícia; para não comprometer o superior papel pastoral que a ele cabe em favor de ambas as partes. No processo breve nenhuma das três dificuldades se apresentam. É verdade que a norma não proíbe expressamente a delegação; mas a mens legislatoris, que desta vez sabemos diretamente sem devê-la deduzir por fontes indiretas, não é na linha de consentir a delegabilidade, vendo os motivos que o prefácio 
do motu proprio expõe como fundamento deste novo dever episcopal. Se pode pensar que existam exceções.

Sobre a decisão, único dever do bispo, necessita distinguir entre decidir e escrever a sentença; ao bispo compete o pressuposto da certeza moral para decidir, embora com o obrigado conselho do instrutor e do assessor. Ao bispo se confia também o modo de escrevê-la, ao passo que seja garantida a motivação e notificação às partes e aos outros interessados; sobre ele, portanto, pesa o dever de fazer com que as razões da decisão sejam compreendidas pelos destinatários. Ele deve fazer também seu o texto, enquanto é obrigado a assinar a sentença. A decisão deve ser afirmativa e nunca negativa, consentindo-se somente o reenvio a exame ordinário em caso de falta de certeza.

$\mathrm{O}$ eventual apelo se prevê somente contra a sentença afirmativa e se presume que será proposto somente pelo defensor do vínculo, enquanto que a proposição das partes não é coerente com o pressuposto do recíproco acordo inicial para seguir esta via. O bispo ao qual se entrega o apelo se supõe que, como o bispo que decidiu em primeiro grau, é obrigado a tomar em consideração os pareceres do instrutor e do assessor, que intervieram na primeira instância, o que sugere que estes sejam expressos por escrito. Com efeito, nesta segunda fase não se prevê nenhuma forma explícita de consulta ao bispo competente para decidir, se bem que nada proíbe que ele se sirva (como consente a qualquer que seja o juiz monocrático o cân. 1424) de assessores.

Nesta via, em termos análogos a quanto acontece pelas sentenças emanadas depois de uma causa tratada pela via ordinária, se prevê a possibilidade de rejeitar a limine do apelo se este aparece de maneira evidente "meramente dilatório" (cân. 1687,4). A diferença com as normas dadas para o processo ordinário (cân. 1680) é que na normativa sobre o apelo contra a sentença do bispo não se estabelece algum trâmite, por isso, se prescinde pelo referir-se de qualquer que seja a comunicação às partes privadas e ao defensor do vinculo, nem a exigência de estabelecer termos para apresentar observações. Que se deva de qualquer forma garantir o intervento do defensor do vínculo, parece evidente de acordo com a previsões gerais do qual se refere o cân. 1433, referindo às obrigações de citar o defensor do vínculo, a qual inobservância provocaria a nulidade dos autos e, nestas causas, tam- 
bém da sentença. Nomeadamente, sendo defensor do vínculo de primeiro grau, o único provável apelante neste gênero de causas, deve-se considerar garantido o intervento do defensor do vínculo de segundo grau, único ao qual cabe o prosseguimento do apelo interposto pelo defensor do vínculo de primeiro grau, além disso renunciar a ele (cân. 1636,2).

Para que um apelo resulte manifestadamente um ato meramente dilatório, e sobretudo para poder confirmar a sentença, se exigirá analisar os autos (e não somente o ato de apelo) e adquirir a certeza moral sobre o fundamento da sentença declarativa da nulidade, objeto da confirmação. No caso em qual o apelo apareça meramente dilatório, o bispo que intervê em segundo grau decidirá o reenvio a um exame ordinário a desenvolver-se, pela primeira vez, mas sempre no tribunal de segunda instância. Nisto se distingue a normativa do processo mais breve daquela prevista pelas decisões análogas no processo documental (cân. 1690, onde se prevê a entrega da causa ao tribunal de primeira instância).

\section{Bibliografia}

A. VAlLInI, Dalle Normae Speciales alla Lex Propria: itinerario di una riforma, en AA. VV., La «Lex Propria» del S.T. della Segnatura Apostolica, Città del Vaticano 2010, 74.

Benedictus PP. XVI, Lex propria Supremi Tribunalis Signaturae Apostolicae, 21.6.2008: AAS, 100 (2008), 513-538.

C. MorÁn Bustos, El proceso "brevior" ante el Obispo Diocesano, en M. E. Olmos Ortega (ed.), Procesos De Nulidad Matrimonial. Tras la reforma del Papa Francesco, Madrid 2016.

C. PEÑA, El nuevo proceso "breviore" coram episcopo: Monitor Ecclesiasticus 130 (2015), 567-593.

C. Peña, La reforma de los procesos canónicos de nulidad matrimonial: el motu proprio "Mitis Iudex Dominus Iesus": Estudios Eclesiásticos 90 (2015), 621-682.

D. Vitali, Verso la sinodalità, Magnano, 2014. 
F. AZNAR GIL, La necesaria madurez y libertad para contraer matrimonio en los casos de embarazo, en AA.Vv, Estudios canónicos en homenaje al profesor D. Lamberto Echevarría, Salamanca 1984, 189-244.

G. MontinI, Gli elementi pregiudiziali del processu brevior, in AA.Vv., Prassi e sfide dopo l'entrata in vigore del m.p. Mitis Iudex Dominus Iesus e del rescriptum ex audientia del 7 dicembre 2015, Città del Vaticano 2018, 62-63.

G. P. Montini, Dopo la decisione giudiziale: appello e altre impugnazioni, en REDAZIONE DI QUADERNI DI DIRITTO ECCLESIALE, La riforma dei processi matrimoniali di Papa Francesco, Milano 2016, 115.

J. LloBell, Alcune questioni comuni ai tre processi per la dichiarazione di nullità del matrimonio previsti dal m.p. "Mitis Iudex", in Seminario di studio presso la Lumsa, 30 ottobre 2015, in http://www.iuscanonicum.it/Llobell_Lumsa.pdf., 7-10.

J. LlOBELL, La delega della potestà giudiziaria nell'ordinamento canonico: Ius canonicum, volumen especial, Escritos en honor de Javier Hervada (1999) 459-472.

L. SABBARESE, Nuove norme per la dichiarazione di nullitá del matrimonio, Bologna 2016.

M. Del Pozzo, Il processo matrimoniale più breve davanti al vescovo, Roma 2016.

M. J. ARroba Conde, Apertura verso il processo amministrativo di nullità matrimoniale e diritto di difesa delle parti: Apollinaris 75 (2002), 774-777.

M. J. Arroba Conde, Cuestiones fundamentales de derecho probatorio canónico, en R. RodRIGUEZ CHACÓn (ed.), Puntos de especial dificultad en derecho matrimonial canónico, sustantivo y procesal, y cuestiones actuales de derecho eclesiástico y relaciones Iglesia - Estado (XXVII Jornada de la asociación de canonistas españoles (11 al 13 abril), Madrid 2007, 111. 
M. J. Arroba Conde, Diritto processuale canonico, Roma ( $6^{\mathrm{a}}$ ed.) 2012.

M. J. ARRoBA CONDE, El principio dispositivo en el proceso contencioso canónico, Roma 1989.

M. J. Arroba Conde, El proceso más breve ante el Obispo, en L. RUANO - C. GUZMÁN (EDD.), Reforma de los procesos de nulidad y otras novedades legislativas de derecho canónico y eclesiástico del Estado, Madrid 2017, 249-278.

M. J. ARROBA CONDE, La nullità insanabile della sentenza per un vizio attinente il procedimento en AA.VA., La "querela nullitatis" nel processo canonico, Città del Vaticano 2005, pp. 145-166.

M. J. ARRoBA CONDE, La procedura extragiudiziale per la dichiarazione di nullità del matrimonio, GRUPPO ITALIANO DOCENTI DIRITTO CANONICO (ed.), Il diritto nel mistero della Chiesa, IV, Città del Vaticano 2014, 173-186.

M. J. ARRoBA CONDE, Prima analisi della riforma del processo canonico di nullità del matrimonio, in PONTIFICIA UNIVERSITÀ LATERANENSE, Convegno: Le litterae Motu proprio sulla riforma dei processi di nullità matrimoniale - una prima analisi, 13 ottobre 2015, em http://www.iuscanonicum.it/prima-analisisulla-riforma-del-processo-di-nullità.

M. J. ARROBA CONDE, Relación entre las pruebas y la comprobación de la verdad en el proceso canónico: Anuario de Derecho canónico 1 (2012), 11-36.

M. J. Arroba Conde, sub cc. 1671-1691, en A. Benlloch PovedA (ed.), Código de derecho canónico. Edición bilingüe, fuentes y comentarios de todos los cánones, Valencia (16 ed.) 2016, 722738.

M. J. ARROBA CONDE, Verità e relazione processuale nell'ordinamento canonico: sfide circa il metodo extragiudiziale, en G. DAlla TORRE - C. Mirabelli (eds.) Verità e metodo in giurisprudenza. Scritti dedicati al cardinale Agostino Vallini 
in occasione del 25 anniversario della consacrazione episcopale, Città del Vaticano 2014, 23-50.

M. MIELE, Il promotore di giustizia nelle cause di nullità del matrimonio, en S. GHERRo (ed.), Studi sul processo matrimoniale canonico, Padova 1991, 133-178.

M. J. ARroba Conde, La pastoral judicial y la preparación de la causa en el motu proprio Mitis Iudex Dominus Iesus, en M.E. Olmos OrTega (ed.), Procesos de nulidad matrimonial tras la reforma del Papa Francesco, Madrid 2016, 63-66).

M. J. ARROBA CONDE, La recente esperienza sinodale in prospettiva canonica: Commentarium pro Religiosis et Missionariis 96 (2015), 263-286.

O. GRAZIOLI, La querela nullitatis: origini, attualità e prospettive di comparazione, Città del Vaticano 2016.

R. BURKE, La procedura amministrativa per la dichiarazione di nullità del matrimonio, en AAVv., I procedimenti speciali nel diritto canonico, Città del Vaticano 1992, 94-98.

Signatura APOSTÓLICA, Declaratio de foro competenti in causis nullitatis matrimonii post sententiam negativam in prima instantia latam, 3.6.1989: Monitur Ecclesiasticus 115 (1990) 230-231.

SignatURA ApOStOliCA, Normae pro Tribunalibus interdiocesanis, vel regionalibus aut interregionalibus, 28 dic. 1970: AAS 67 (1971), 486-492.

Z. GROCHOLEWSKI, Dichiarazioni di nullità di matrimonio in via amministrativa da parte del Supremo Tribunale della Segnatura Apostolica: Ephemerides Iuris Canonici 37 (1981)177-185.

Z. GROCHOLEWSKI, La facoltà del congresso della Segnatura Apostolica di emettere dichiarazioni di nullità di matrimonio in via amministrativa, en AAVV., Investigationes teologico-canonicae, Roma 1978, 211-218. 